\title{
Correction to: Expression of B7-H6 expression in human hepatocellular carcinoma and its clinical significance
}

Lujun Chen ${ }^{1,2,3}$, Jun Feng ${ }^{1,2,3}$, Bin $\mathrm{Xu}^{1,2,3}$, You Zhou ${ }^{1,2,3}$, Xiao Zheng ${ }^{1,2,3}$, Changping Wu $\mathbf{u}^{1,2,3}$ and Jingting Jiang ${ }^{1,2,3^{*}}$

\section{Correction to: Cancer Cell Int (2018) 18:126} https://doi.org/10.1186/s12935-018-0627-7

Following publication of the original article [1], the authors reported a typing mistake in the title. In this Correction the incorrect and correct titles are shown.

Incorrect title:

Expression of B7-H6 expression in human hepatocellular carcinoma and its clinical significance

The correct title is:

B7-H6 expression in human hepatocellular carcinoma and its clinical significance

\section{Author details}

${ }^{1}$ Department of Tumor Biological Treatment and Research Center for Cancer Immunotherapy Technology of Jiangsu Province, The Third Affiliated Hospital of Soochow University, Changzhou 213003, Jiangsu, China. ${ }^{2}$ Jiangsu Engineering Research Center for Tumor Immunotherapy, The Third Affiliated Hospital of Soochow University, Changzhou 213003, Jiangsu, China. ${ }^{3}$ Institute of Cell Therapy, The Third Affiliated Hospital of Soochow University, Changzhou 213003, Jiangsu, China.

The original article can be found online at https://doi.org/10.1186/s1293 5-018-0627-7.

\section{Publisher's Note}

Springer Nature remains neutral with regard to jurisdictional claims in published maps and institutional affiliations.

Received: 6 September 2018 Accepted: 6 September 2018 Published online: 10 September 2018

\section{Reference}

1. Chen L, Feng J, Xu B, Zhou Y, Zheng X, Wu C, Jiang J. Expression of B7-H6 expression in human hepatocellular carcinoma and its clinical significance. Cancer Cell Int. 2018;18:126. https://doi.org/10.1186/s1293 5-018-0627-7.

\footnotetext{
${ }^{*}$ Correspondence: jiangjingting@suda.edu.cn

${ }^{1}$ Department of Tumor Biological Treatment and Research Center

for Cancer Immunotherapy Technology of Jiangsu Province, The Third Affiliated Hospital of Soochow University, Changzhou 213003, Jiangsu,

China

Full list of author information is available at the end of the article
} 